\title{
Clinical Events Assessment Reason Not Done
}

National Cancer Institute

\section{Source}

National Cancer Institute. Clinical Events Assessment Reason Not Done. NCI Thesaurus.

Code C87842.

The explanation given as to why a clinical event was not assessed. 